\title{
Patient-Prosthesis Mismatch: State of the Art and Implications for Long Term Results
}

\author{
Paolo Nardi*, Marco Russo, Guglielmo Saitto and Giovanni Ruvolo \\ Cardiac Surgery Division, Tor Vergata University Policlinic of Rome, Italy
}

Submission: March 12, 2017; Published: April 13, 2017

*Corresponding author: Paolo Nardi, Tor Vergata University of Rome, Tor Vergata Policlinic, Viale Oxford 81, 00133 Rome, Italy, Tel: +39(06)20903536; Fax: +39(06)20903538; Email: pa.nardi4@libero.it

\section{Mini Review}

Patient-prosthesis mismatch (PPM) was reported for the first time by Rahimtoola [1] in 1978 and it occurs when the effective orifice area (EOA) indexed for the body surface area (BSA) is less than that of a normal human valve. Several studies using the indexed EOA have shown the negative impact of PPM on clinical outcomes: in fact, it seems to be related with less improvement in symptoms, i.e. functional class, lesser regression of left ventricular mass and with an higher rate of early mortality in particular when left ventricular low ejection fraction is associated and adverse events during long-term follow-up [2-3]. Although some studies [4] suggest that an increased mortality can occur only in presence of a critical level of obstruction, i.e. PPM $<0.4 \mathrm{~cm}^{2} / \mathrm{m}^{2}$, numerous recent studies showed a negative outcome also in presence of a less degree of PPM.

The impact of PPM on in hospital mortality after aortic valve replacement may be particularly important: the left ventricle is more vulnerable to increased stress and may be more sensitive to increase after load associated with PPM in the postoperative course. Pibarot et al. [2] following 392 patients during a 7-year follow-up after AVR, found that cardiac index decreased significantly after 3 years from operation only in patients with PPM $(\mathrm{p}<0.05)$, and that the greatest deterioration was seen in presence of a severe PPM, i.e. indexed EOA $<0.65 \mathrm{~cm}^{2} /$ $\mathrm{m}^{2}$. Moreover, PPM was associated with less postoperative improvement of NYHA functional class $(\mathrm{p}<0.009)$. Rao et al [5] in 2,154 patients undergone AVR found a 30-day mortality significantly higher in patients with evidence of PPM in comparison with patients without PPM $(7.9 \%$ vs. $4.6 \%$, p<0.05).

Milano et al. [6] in 229 patients subjected to aortic valve replacement with $19 \mathrm{~mm}$ and $21 \mathrm{~mm}$ St. Jude Medical standard prostheses reported a 10-year better freedom from cardiac events in patients with not significant PPM (indexed EOA $>0.90 \mathrm{~cm}^{2} / \mathrm{m}^{2}$ ) in comparison with those affected by moderate PPM (indexed EOA $0.60-0.90 \mathrm{~cm} 2 / \mathrm{m} 2$ ) and severe PPM (indexed EOA $\left.<0.60 \mathrm{~cm}^{2} / \mathrm{m}^{2}\right)(\mathrm{p}<0.05)$. All results suggest that PPM may have a detrimental impact on the normalization of the left ventricular mass and function during follow-up after AVR. As suggested by these studies, it is possible that PPM can have a negative impact on long-term survival for the fact that bioprosthetic valves progressively deteriorate due to leaflets' calcification. This deterioration becomes more frequent 8-10 years after their implant. Patients operated on with a moderate or severe PPM already present a degree of the obstruction of the left ventricular outflow. Any further decrease in EOA during follow-up could lead to a more severe obstruction, with a negative clinical impact or need of re-operation. In contrast, patients without PPM have a substantial valve EOA "reserve" that could permit to better tolerate a progressive reduction of the EOA that may occur as a consequence of leaflets' calcification in case of bioprosthetic valves, or pannus overgrowth in case of mechanical prostheses.

On the other hand, a strict relation between PPM and long term mortality was not found in other papers. Ruel et al. [7] in 1,563 patients who underwent AVR and followed up to 15 years, did not find PPM, defined as indexed EOA $<0.80 \mathrm{~cm}^{2} /$ $\mathrm{m}^{2}$, significantly associated with all-cause mortality (HR:1.4, $\mathrm{p}=0.15$ ), but, on the contrary, PPM was a significant predictor of congestive heart failure events (HR:1.6, p=0.04). Hanayama et al. [8] in their paper published in 2002, in 1,037 patients who underwent AVR with mechanical or biological prostheses found no significant relationship between severe PPM and regression of left ventricular hypertrophy or a negative impact on mid-term survival. However, follow-up data were limited at 7 years, a great number of patients during follow-up remained with a higher abnormal left ventricular mass index, freedom from III-IV NYHA class at 6 years was less than $80 \%$.

Although, relationship between PPM and structural valve deterioration has been weel investigated. Flameng et al. [9] in a recently published study on 648 patients (mean age $74+5$ years) who underwent AVR with biological valves analyzed the 
occurrence of structural valve degeneration (SVD) at 10 years of follow-up.

SVD was diagnosed in $12.6 \%$ of patients. PPM and the absence of antimineralization treatment of the biological valve was found as independent predictors of SVD. In detail, patients receiving a non-treated valve show a freedom of SVD at 10 years follow-up of $70+4.3 \%$ vs $90.9 \pm 3.6 \%$ in those receiving a treated valve $(\mathrm{p}<0.0001)$. Patients having PPM and receiving a non-treated valve showed a freedom of SVD at 10 years of only $59.8+7.0 \%$ vs $88.7+3.6 \%$ in patients also having PPM but receiving a treated valve $(\mathrm{p}<0.0001)$. In patients not having PPM, the corresponding values were $78.0+4.3 \%$ and $92.7+3.4 \%$ for non-treated vs treated valves, respectively $(\mathrm{p}=0.01)$.

In a recent multi-center study performed by Bavaria et al. [10] the Trifecta valve results as an unique pericardial bioprosthesis that provides excellent hemodynamic performance while providing ease of implantation. In this study Trifecta bioprosthesis was implanted in 1,014 patients (mean age of 72.5 years). Early ( $\leq 30$ day) mortality occurred in 18 patients $(1.8 \%)$, and there were 23 late ( $\geq 31$ days) deaths. There were no early valve thrombosis, endocarditis, or clinically significant hemolysis, and 5 late valve explants, only one due to SVD. At the time of discharge, average mean gradients ranged from 9.3 to $4.1 \mathrm{mmHg}$ and EOA ranged from 1.58 to $2.50 \mathrm{~cm}^{2}$ for valve sizes 19 to $29 \mathrm{~mm}$.

In an elegant study on the fluid-dynamic results obtained comparing four pericardial aortic bioprostheses (Magna Ease, Mitroflow, Trifecta, and Soprano-Armonia) implanted in small porcine aortic roots, Tasca et al. [11] reported after Trifecta implantation, in comparison with the other implanted bioprostheses, better EOA $(2.3+0.3$ vs $1.57+0.2$ [Magna Ease], $1.77+0.2$ [Mitroflow], $1.75+0.2 \mathrm{~cm}^{2}$ [Soprano-Armonia], $\mathrm{p}<0.001)$, lower mean gradients $(6.1+2$ vs $13.2+3,10.2+3$, $9.6+2 \mathrm{mmHg}, \mathrm{p}<0.001)$, and lower valve resistance $(33+10$ vs $69+16,55+13,51+11$ dyn*s $/ \mathrm{cm}^{5}, \mathrm{p}<0.001$ ), showing that the bioprostheses with the pericardium outside the stent (i.e., the Trifecta valve) are more efficient, thus preventing PPM and structural valve deterioration.

\section{Conclusion}

Current knowledge would suggest that moderate PPM should be avoided in patients with certain condition, i.e. depressed left ventricular function, severe left ventricular hypertrophy, age $<70$ years, athletic lifestyle, elderly patients seeking enhanced quality of life, concomitant mild or moderate mitral regurgitation not addressed by surgery. On the contrary, severe PPM should be avoided in all cases. The use of a newer better performing and at easy implantation bioprostheses can significantly decrease the occurrence of PPM, without any increased operative risk related with the requirement of more demanding and complex surgical techniques to the annulus and aortic root enlargement.

\section{References}

1. Rahimtoola SH (1978) The problem of valve prosthesis-patient mismatch. Circulation 58(1): 20-24.

2. Pibarot P, Dumesnil JG, Lemieux M, Cartier P, Métras J, et al. (1998) Impact of prosthesis-patient mismatch on hemodynamic and symptomatic status, morbidity, and mortality after aortic valve replacement with a bioprosthetic heart valve. J Heart Valve Dis 7(2): 211-218.

3. Blackstone EH, Cosgrove DM, Jamieson WR, Birkmeyer NJ, Lemmer JH, et al. (2003) Prosthesis size and long-term survival after aortic valve replacement. J Thorac Cardiovasc Surg 126(3): 783-796.

4. Daneshvar S, Rahimtoola SH (2012) Valve prosthesis-patient mismatch (VP-PM): a long-term perspective. J Am Coll Cardiol 60(13): 11231135.

5. Rao V, Jamieson WR, Ivanov J, Armstrong S, David TE (2000) Prosthesispatient mismatch affects survival following aortic valve replacement. Circulation 102(19 Suppl 3): 1115-1119.

6. Milano AD, De Carlo M, Mecozzi G, D’Alfonso A, Scioti G, et al. (2002) Clinical outcome in patients with $19 \mathrm{~mm}$ and $21 \mathrm{~mm}$ St. Jude aortic prostheses: comparison at long-term follow-up. Ann Thorac Surg 73(1): 37-43.

7. Ruel M, Rubens FD, Masters RG, Pipe AL, Bédard P, et al. (2004) Late incidence and predictors of persistent or recurrent heart failure in patients with aortic prosthetic valves. J Thorac Cardiovasc Surg 127(1): 149-159.

8. Hanayama N, Christakis GT, Mallidi HR, Joyner CD, Fremes SE, et al. (2002) Patient prosthesis mismatch is rare after aortic valve replacement: valve size may be irrelevant. Ann Thorac Surg 73(6): 1822-1829.

9. Flameng W, Rega F, Vercalsteren M, Herijgers P, Meuris B (2014) Antimineralization treatment and patient-prosthesis mismatch are major determinants of the onset and incidence of structural valve degeneration in bioprosthetic heart valves. J Thorac Cardiovasc Surg 147(4): 1219-1224.

10. Bavaria JE, Desai ND, Cheung A, Petracek MR, Groh MA, et al. (2014) The St Jude Medical Trifecta aortic pericardial valve: results from a global, multicenter, prospective clinical study. J Thorac Cardiovasc Surg 147(2): 590-597.

11. Tasca G, Vismara R, Fiore GB, Mangini A, Romagnoni C, et al. (2015) Fluid-dynamic results of in vitro comparison of four pericardial bioprostheses implanted in small porcine aortic roots. Eur J Cardiothorac Surg 47(2): e62-e67. 
This work is licensed under Creative Commons Attribution 4.0 License DOI: $10.19080 / J O C C T .2017 .04 .555643$
Your next submission with Juniper Publishers will reach you the below assets

- Quality Editorial service

- Swift Peer Review

- Reprints availability

- E-prints Service

- Manuscript Podcast for convenient understanding

- Global attainment for your research

- Manuscript accessibility in different formats ( Pdf, E-pub, Full Text, Audio)

- Unceasing customer service

Track the below URL for one-step submission https://juniperpublishers.com/online-submission.php 